\title{
Scenes from a Restaurant: Privacy Regulation in Stressful Situations
}

\author{
Stephani K.A. Robson \\ Cornell University
}

\begin{abstract}
Stress results when an individual has less control over an environment or a situation than is desired. One way of regaining control and reducing stress is to regulate privacy by screening the self from spatial, visual or acoustical invasion. This study examined the use of architectural features to regulate privacy under hypothetical situations that are likely to generate low, moderate and high stress, comparing the seating choices of males and females in a variety of dining scenarios in a restaurant. In more stressful circumstances such as those associated with a job interview, participants chose restaurant seating bounded by more architectural features than they did in more relaxed dining situations such as dining with friends. Males and females appeared to be different in their responses to moderate and high stress situations. These results have implications for designers of secondary settings where stressful interactions are likely to take place.
\end{abstract}

\section{Introduction}

Evans (1979) has stated that the key element tying together major environmental psychology models is the human response to stress. One of the most frequently studied environmental stressors has been perceived or actual invasions of privacy. While there are several conceptualizations of privacy in the literature, in general privacy can be said to be a means of obtaining freedom to choose how much of ourselves to expose to observers, with exposure not being strictly limited to being seen by others (Proshansky, Ittelson, \& Rivlin, 1974; Westin, 1967). Privacy can be violated physically by means of spatial encroachment, visually by an extended unwelcome gaze, or acoustically via loud conversation or other noise stimuli. All three types of privacy invasion create discomfort in part because they presume a level of intimacy that is inappropriate for the circumstance and/or for the relation- ships between the self and those encroaching upon the self's personal sphere (Argyle \& Dean, 1965).

Regardless of its form, the discomfort of an invasion of privacy creates emotional stress, and initiates a variety of conscious and unconscious behaviors that attempt to regulate personal boundaries (Altman, 1975). These may take the form of movement away from the invasive individual or group to increase interpersonal distance, reorientation of the face or body to reduce visual contact, or complete retreat to 
another environment, all of which represent types of avoidance behaviors (Fried \& DeFazio, 1974; Sommer, 1969). Privacy regulation may also involve the use of physical barriers to reduce the amount of stimulation as well as reduce the uncertainty associated with exposure, giving the individual a sense of control over an environment (Desor, 1972; Kupritz, 2000). Standing or sitting next to walls, partitions, or other features of the environment protects the user from spatial invasion on at least one side, and depending on the dimensions and composition of the feature may also provide a measure of visual and possibly even acoustical screening. This type of avoidance behavior can be pre-emptive: it may be adopted in settings where an invasion of personal space is possible but has not actually occurred. For example, Baum and Greenberg (1975) have shown that the potential for spatial invasion can influence the choice of seating, with those anticipating crowding choosing seats in a corner or along a wall, making use of the physical environment to help regulate privacy.

While stress may stem from privacy invasion, it also may result from a perceived power differential between the participants in an interaction. The vulnerability felt by an individual in a less powerful position can trigger a number of avoidance responses, including averting of the eyes, body repositioning, and pulling in of the extremities (Dosey \& Meisels, 1969; Webb \& Weber, 2003). Those with greater power are more likely to adopt closer interpersonal distance with subordinates (Dean, Willis, \& Hewitt, 1975; Lott \& Sommer, 1967; Schwartz, 1968), whereas those with less power are apt to feel uncertain and anxious during social interactions with superiors (Keltner, Gruenfeld, \& Anderson, 2003; Sommer, 1969), and to create greater interpersonal distance from those with higher status than themselves (Hall, 1966). Being able to control personal space helps to alleviate some of the stress associated with an imbalance of power; privacy can help to nullify the power that others may have over us due to their relative position or status (Kelvin, 1973). However, the privacy regulation mechanisms selected to respond to power-related stress must be compatible with the situation and carefully calibrated in order to not give offense to the more powerful party. For example, it may be perceived as insubordinate for a worker to back away from an employer who may be closer to the employee than is comfortable.

Gender also influences privacy regulation and proxemic behaviors. Females appear to be more comfortable with closer interpersonal distance when approaching another face-to-face, whereas males adopt closer spacing when approaching others from the side (Horowitz, Duff, \& Stratton, 1964). Men typically adopt greater interpersonal distances than do women when interacting in same-sex groups, and women will generally be approached more readily and more closely than will men, regardless of the gender of the participant (Burgoon, 1978; Mehrabian \& Diamond, 1971). Although both 
genders dislike invasions of privacy, males generally respond more negatively to spatial intrusion than do females, particularly if the intruder is another male (Fisher \& Byrne, 1975; Patterson, Mullens, \& Romano, 1971). These differences may suggest specific architectural solutions for social settings that are likely to be used by one gender over another. While both genders appear to rely on design features to regulate privacy, the greater territoriality exhibited by males might indicate that they would prefer seating that reduces the potential for encroachment (Kaya \& Burgess, 2007; Kaya \& Weber, 2003). If this is the case, one might expect men to choose corner seating more frequently than women. However, females have been shown a greater tendency to feel "observed" or exposed when interacting with others and that they feel more discomfort than males do when in this position, a response that is particularly amplified when there is a power differential between the interactants (Argyle \& Williams, 1969). Therefore it seems likely that women would prefer seating with the greatest degree of architectural screening, especially when the situation is stressful in some way. So far, there does not appear to be any research in the literature that sorts out conclusively whether males or females have the stronger preference for adopting more defensive proxemic postures while under stress.

\section{Research Study}

It might be expected that the more stressful the situation, the greater the reliance would be on regulating privacy, even if privacy invasion were not actually the cause of the stress. Females under stress might be expected to adopt more privacy regulation behaviors than males in a similar situation because of their greater sensitivity to stress (Jick \& Mitz, 1985), the higher value that females place on privacy (Walden, Nelson, \& Smith, 1981), and their increased discomfort at being the "observed" in a potentially stressful interaction (Argyle \& Williams, 1969).

In settings where common avoidance behaviors such as moving away or reducing eye contact are socially unacceptable or even impossible, it may be that all individuals will be more likely to try to regulate privacy by using the physical environment as a barrier or screen (Evans \& Lepore, 1992; Kupritz, 2000). Architectural elements commonly used for this purpose have been collectively termed "anchors" (Robson, 2002). Anchors are design features that offer the potential for limiting access to the person, which may be permanent (walls, columns, windows, and partitions) or movable (furniture or plants), but in either case provide temporary screening from the sight, sound, or proximity of others. It is very possible that matching seating characteristics, such as the number and type of anchors, with the needs of users in a given situation might reduce situational stress and possibly increase satisfaction with an experience. 
This study seeks to examine the influence of stress on the use of architectural anchors in a restaurant setting and to determine whether there are gender differences in using anchors as a form of privacy regulating behavior. The specific hypotheses of the study are threefold:

- $\quad \mathrm{H}_{1}$ : subjects will select restaurant seats with more anchors in a stressful situation.

- $\quad \mathrm{H}_{2}$ : subjects will select restaurant seats with fewer anchors in a non-stressful situation.

- $\quad \mathrm{H}_{3}$ : females in a stressful situation will select restaurant seats with more anchors than will males in the same situation.

A hypothetical restaurant environment was chosen for this study because of its familiarity as a setting for interactions between equals as well as among groups of mixed status. Restaurants also offer a number of different seating locations that are roughly equivalent in terms of the service experience but have different relationships to windows, walls, doorways, and other architectural features. Further, when conditions permit, restaurants may allow patrons to choose their own table locations, lending validity to using this setting as a venue for soliciting seating preferences under a variety of scenarios.

A perceived power differential among dining participants was selected as the manipulation for stress in this study. Under this form of stress, the use of architectural anchors may be more likely to occur because privacy regulation in the form of self-screening is a stress-reducing avoidance behavior that is unlikely to cause offense or be taken personally by the individual with greater power in the interaction. Thus choosing seating that is architecturally anchored is likely to be a reasonable indicator of attempted privacy regulation in stressful situations.

\section{Method}

\subsection{Participants}

A sample of 478 college students was recruited from a large introductory economics class and from campus organizations at a large Northeastern US university. Participants ranged in age from 18 to 26 years, and were generally evenly split between male $(n=234)$ and female $(n=244)$. Participation was strictly voluntary and was not compensated. 


\subsection{Procedure}

Participants were asked to complete a short questionnaire that was presented as being a tool to help a team of architects create the optimal seating layout in a new restaurant. This questionnaire outlined a series of brief written scenarios for typical dining experiences, accompanied in each case by a simplified floor plan of the proposed dining room (see Fig. 1). Scenarios have been shown to be an effective way to elicit affective responses to environments when coupled with a graphical representation of the space under study (Hui \& Bateson, 1991; Sommer \& Becker, 1969). Tables positioned along the perimeter of the room were categorized as "anchored", with tables in the corners having two anchors, tables next to windows or along walls away from corners having one anchor, and tables in the middle of the space having no anchors at all. Corner tables were presumed to offer the greatest degree of privacy because they protect users from encroachment on two sides; tables with one anchor were chosen to represent a

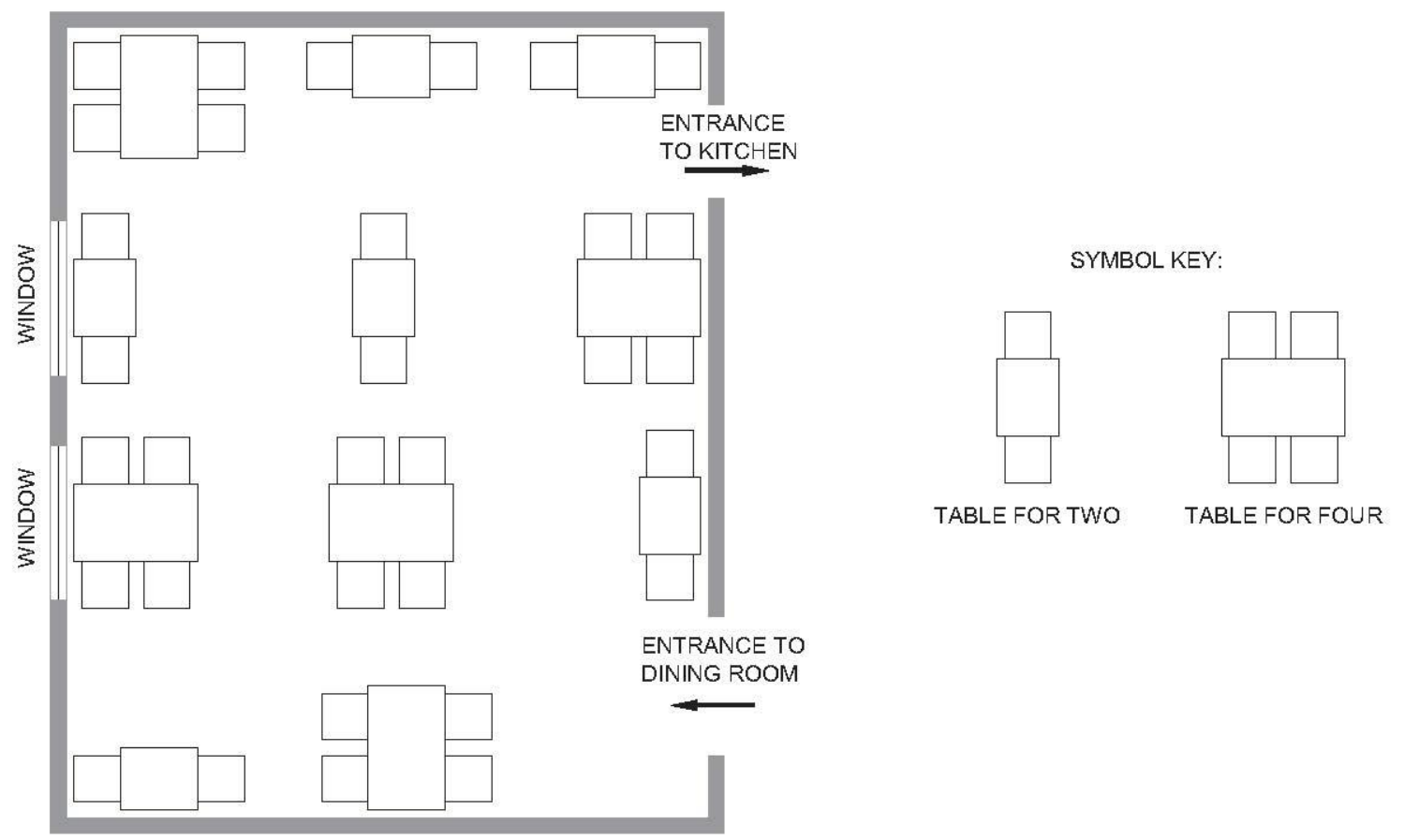

Fig. 1. Hypothetical restaurant layout.

moderate level of privacy because one side of the table is protected from spatial and visual invasion; and unanchored tables were assumed to offer the poorest opportunity for using the environment for privacy regulation because these tables grant no architectural protection from approach or observation by others. Table categories were further broken down by type of anchor to control for possible effects of particular anchor characteristics. Participants were asked to respond to each scenario by indicating 
which seat they would prefer to occupy in the dining room under that scenario. The written scenarios outlined the following dining experiences:

- $\quad$ Dining with three family members;

- $\quad$ Dining with three friends;

- $\quad$ Dining with a professor;

- $\quad$ Dining while being interviewed for a job.

The scenarios for this study were selected to reflect realistic dining occasions that varied in terms of the relationships and perceived power among the participants and the likely degree of stress that each scenario would engender. Students' natural anxiety about being evaluated by potential employers as well as the common practice of interviewing job finalists over a meal led to the choice of the interview scenario for a "high stress" condition, whereas dining with a professor was selected to represent a moderately stressful interaction. Dining with friends or family was chosen to represent a "low stress" interaction. (The wording for the scenarios used for this study appears in the appendix.)

The questionnaire closed with a few basic demo- graphic questions including gender and age. The questionnaire was pre-tested with a small $(n=14)$ convenience sample; none of the pre-testers identified stress as the key construct being examined, providing support that there were few if any priming effects from the instrument. Minor changes to the written scenarios were made to increase comprehension and the questionnaire administered to the volunteer participants during classes or at meetings of their campus organizations.

\section{Results}

Despite being instructed to indicate seat preference on the restaurant floor plan, many subjects indicated only a preference for a given table, and therefore the preference measurement was revised to be table location rather than individual seat location. This revision did not compromise the study's ability to identify whether stressful situations lead to a preference for additional anchors.

Table 1 summarizes the table preferences under the four scenarios. In the low stress conditions of dining with family and with friends, the majority of participants selected a table with a single anchor, either along the window (friends: 58.6\%; family: 70.2\%) or along a wall (friends: $11.7 \%$; family: $7.0 \%$ ). Tables with two anchors were the next most frequently selected location (friends: $15.6 \%$; family: 12.8\%), with unanchored tables being the selected least often (friends: $12.8 \%$; family: $8.5 \%$ ). Table choice 
between the dining with friends and dining with family scenarios was clearly different $\left(X^{2}=15.675\right.$, $p<.003, d f=4)$, although tables with only one anchor were selected most often in both low perceived stress scenarios.

Under the moderate stress scenario, tables with a single anchor were still selected most often (52.5\%) but there was a marked increase in the selection of corner tables that had two anchors (26.4\%). In the scenario with the highest stress, the interview, corner tables were selected $45.6 \%$ of the time as opposed to tables with a single anchor (38.2\%) or no anchor (13.4\%). Statistically, the differences in table preference were strongly significant across the three levels of stress: low stress versus moderate stress $\left(X^{2}=107.794, p<.000, d f=4\right)$; low stress versus high stress

Table 1

Table preference by scenario.

\begin{tabular}{|c|c|c|c|c|c|}
\hline & Friends (low stress) & Family (low stress) & Professor (moderate stress) & Interview (high stress) & Total \\
\hline Corner table ( 2 anchors) & $15.6 \%$ & $12.8 \%$ & $26.4 \%$ & $45.6 \%$ & $25.1 \%$ \\
\hline Window table ( 1 anchor) & $58.6 \%$ & $70.2 \%$ & $35.2 \%$ & $26.0 \%$ & $47.5 \%$ \\
\hline Other anchored table ( 1 anchor) & $11.7 \%$ & $7.0 \%$ & $17.3 \%$ & $12.2 \%$ & $12.0 \%$ \\
\hline Unanchored table (0 anchors) & $12.8 \%$ & $8.5 \%$ & $18.8 \%$ & $13.4 \%$ & $13.4 \%$ \\
\hline No preference & $1.3 \%$ & $1.5 \%$ & $2.3 \%$ & $2.8 \%$ & $2.0 \%$ \\
\hline Total & 469 & 469 & 469 & 469 & 1876 \\
\hline
\end{tabular}

Table 2

Table preference by gender across scenarios.

\begin{tabular}{|c|c|c|c|c|c|c|c|c|}
\hline & \multicolumn{2}{|c|}{ Friends (low stress) } & \multicolumn{2}{|c|}{ Family (low stress) } & \multicolumn{2}{|c|}{ Professor (moderate stress) } & \multicolumn{2}{|c|}{ Interview (high stress) } \\
\hline & $\mathrm{F}$ & M & $\mathrm{F}$ & M & $\mathrm{F}$ & M & $\mathrm{F}$ & M \\
\hline Corner & $16.3 \%$ & $14.8 \%$ & $12.1 \%$ & $13.5 \%$ & $30.1 \%$ & $22.6 \%$ & $43.5 \%$ & $47.8 \%$ \\
\hline Window & $61.9 \%$ & $55.2 \%$ & $73.2 \%$ & $66.9 \%$ & $37.7 \%$ & $32.6 \%$ & $31.4 \%$ & $20.4 \%$ \\
\hline other anchored & $8.4 \%$ & $15.2 \%$ & $3.8 \%$ & $10.4 \%$ & $7.9 \%$ & $27.0 \%$ & $11.3 \%$ & $13.0 \%$ \\
\hline Unanchored & $12.1 \%$ & $13.5 \%$ & $8.8 \%$ & $8.3 \%$ & $20.5 \%$ & $17.1 \%$ & $10.0 \%$ & $17.1 \%$ \\
\hline No preference & $1.3 \%$ & $1.3 \%$ & $2.1 \%$ & $.9 \%$ & $3.8 \%$ & $.9 \%$ & $3.8 \%$ & $1.7 \%$ \\
\hline Total & 239 & 230 & 239 & 230 & 239 & 230 & 239 & 230 \\
\hline
\end{tabular}

$\left(X^{2}=222.307, \mathrm{p}<.000, d f=4\right) ;$ and moderate stress versus high stress $\left(X^{2}=38.887, \mathrm{p}<.000, \mathrm{df}=4\right)$. These findings indicate that as the situation became more stressful, participants were more likely to choose seating with multiple architectural anchors.

Given that females may be more sensitive to power differential than males (Keltner et al., 2003), a comparison of female to male responses in each scenario was performed (see Table 2). In the friends scenario, females and males did not respond significantly differently $\left(X^{2}=5.933, p<.204, \mathrm{df}=4\right)$, but their 
differing table choices in the family scenario approached statistical significance $\left(X^{2}=9.442, \mathrm{p}<.051, d f\right.$ =4). Females were more likely than males to choose a window table in the family scenario than were males, although both males and females were equally likely to choose a table with one anchor when dining with family members.

In the more stressful scenarios, men and women were clearly and statistically different. In the moderate stress scenario, women were more likely to choose a corner table than men (females: $30.1 \%$; males: 22.6\%). In the high stress condition, this difference was reversed: $43.5 \%$ of women preferred a corner table while being interviewed, while $47.8 \%$ of men chose a corner table in this scenario. In both cases, the difference across the genders is significant (moderate stress: $X^{2}=32.847, p<.000, d f=4$; high stress: $\left.X^{2}=12.079, \mathrm{p}=.017, d f=4\right)$.

The analysis indicates that individuals are more likely to choose a table that offers more anchors and thus more visual screening in situations that are likely to produce stress, and that there is a difference in response between men and women as the degree of stress increases. Women were more likely to choose a table with two anchors in the moderate stress condition, whereas men were more likely to choose a table with two anchors in the high stress condition.

\section{Discussion}

Stressful situations may lead to behaviors that offer more behavioral control and reduce the potential for unwanted intimacy. One such behavior is to seek out architectural features that can serve as physical, visual, and/or acoustical barriers. As this study shows, this type of privacy regulating behavior appears to take place even in hypothetical situations and in settings over which the user has minimal control, such as the commercial environment of a restaurant.

In situations where there was likely to be low stress, individuals most often chose a table with a single architectural anchor in the form of a wall or a window rather than tables in a corner or in the middle of a space. The choice of a table with at least one anchor is not surprising, as it has been shown that people often prefer to position themselves next to architectural features in public places when it is convenient to do so (Whyte, 1980). This positioning allows privacy to be regulated more effectively and reduces the potential for spatial invasion by strangers (Altman, 1975).

As the power differential between individuals represented in the scenario became more marked, participants indicated an increasing preference for tables with more than one anchor. In the moderately 
stressful circumstance of a meal with a familiar superior (in this case, a professor), tables with a single anchor were preferred more often, although women were more likely to choose a corner table with two anchors than were men. In the most stressful scenario-the job interview-participants chose a corner table more than any other table type regardless of gender. These findings provide support to Hall's (1966) assertion that power is influential in our use of space. As predicted, individuals confronted with a stressful scenario in which there was a significant difference in power between the interactants chose seating that increased their ability to screen themselves from invasions of privacy, even when such an invasion did not appear imminent. Gender differences suggested in the literature were apparent, although not always in the hypothesized direction: in the most stressful circumstances, men were more likely to select heavily anchored seats than women were.

An interesting and unanticipated finding was the difference in table preference between the "dining with friends" and the "dining with family" scenarios. Window tables were much more likely to be selected in the family scenario than in the friend scenario, while other table choices were more similar across the two scenarios. The reasons for this difference in table preference are unclear. Both scenarios were assumed to be relatively unstressful, although for many people, family meals may carry emotional connotations that could be uncomfortable. But if the dynamics of a family meal were to make dining with family more stressful, it might be expected that a corner table would be chosen more frequently under this scenario than would be the case for dining with friends. The data shows the opposite: corner tables were relatively infrequently chosen in both scenarios, and were more often chosen in the friends scenario than in the family scenario. A preference for being close to a window in many building types has been demonstrated (Vischer, 1996), but it remains unclear why this preference should be greater on occasions when we dine with family rather than friends. Further study is clearly needed to confirm and explore this phenomenon. Post-hoc interviewing was not performed in this study due to the high number of participants tested, but such an approach would help determine whether family interaction is indeed more stressful than was anticipated and may inform future research.

In this study, the genders of the hypothetical interactants in each scenario were not specified. It is possible that the response to the scenarios would vary from these findings if the participants were informed that they would be interacting with someone of the same versus the opposite gender. Mixedsex interactions tend to take place at a closer interpersonal distance than same-sex interactions (Duke \& Nowicki, 1972) and there are multiple studies that indicate that interactions that include women as participants feel more intimate to the participants (e.g. Wheeler, Reis, \& Nezlek, 1983). So the 
composition of the pair or group could influence the degree of perceived intimacy and in turn affect the desire to regulate privacy and thus the use of anchors in seat selection. Replication of this study with scenarios that specify gender would be valuable in determining whether anchoring behaviors differ in same-sex versus mixed-sex situations.

This study used written scenarios and a diagram to elicit responses from subjects, an approach which some might construe as lacking ecological validity when compared with controlled experiments or field studies. Further, stress was not specifically measured but was rather inferred as a natural response to the scenarios presented, with support from feedback received during the pre-testing of the questionnaire. A future approach might be to perform some form of manipulation check on the stress induction for each scenario, but care must be taken to ensure there is no priming effect. Projection techniques such as the one adopted for this study have been used successfully to identify seating preferences during different types of interaction (Sommer, 1965) and to determine reactions to a lack of perceived spatial control (Hui \& Bateson, 1991; see also a summary of multiple studies in Hall, Coats, \& LeBeau, 2005). In addition, it is unlikely that a field setting for a study of this type would generate an accurate picture of seating choice because patrons are not always able to choose their own particular table in a full-service restaurant. Even if in reality their choices are not often available, dining patrons clearly do have preferences, and these are much easier to ascertain using a projective methodology such as the one adopted here than they would be in a field experiment.

While this study provides evidence that stress from a power differential may increase the use of architectural anchors to regulate privacy, more work needs to be done to confirm this behavior across multiple scenarios and different sources of stress. The more relaxed environment of a bar or lounge, for example, may encourage a greater degree of intimacy than is typically seen in a restaurant and thus might alter the perceived need for privacy, depending on the status and genders of the interactants. The anticipated length of the interaction might also influence the use of anchors to regulate space; a very brief spatial invasion does not appear to stimulate the same degree of discomfort as one that takes place over time (Altman, 1975). A future stream of research might address all of these factors in more detail to further our knowledge of how stress mediates the use of architectural features to control privacy in public settings.

The findings from this initial study can provide guidance to designers who are creating public environments in which there is a potential for stressful interactions. Providing a physical setting that helps its users feel more comfortable and in control over their experience may have positive effects on 
both satisfaction (Charles \& Veitch, 2002) and, in the case of restaurants and other service settings, possibly beneficial financial results (Kimes \& Robson, 2004). Comfortable guests might exhibit approach behaviors such as increased purchases or more favorable evaluations of the environment, both of which are positive outcomes for commercial settings (Wakefield \& Blodgett, 1996). Understanding the interaction between circumstance and patrons' uses of the environment can only improve our ability to create effective public environments.

\section{Acknowledgements}

The author wishes to thank her colleagues Sheryl Kimes and Anne Vittoria for their valuable input into earlier drafts of this article, and the four anonymous reviewers whose comments and suggestions were enormously helpful.

\section{Appendix. Scenarios}

A. You are out for a casual dinner with three members of your family. In which seat would you prefer to sit?

B. You are out for a casual dinner with three of your friends. In which seat would you prefer to sit?

C. You are out for lunch with a professor. In which seat would you prefer to sit?

D. You are being interviewed for a job over lunch at a restaurant. In which seat would you prefer to sit?

\section{References}

Altman, I. (1975). The environment and social behavior. Monterey, CA: Brooks-Cole.

Argyle, M., \& Dean, J. (1965). Eye-contact, distance and affiliation. Sociometry, 28, 289-304.

Argyle, M., \& Williams, M. (1969). Observer or observed? A reversible perspective in person perception.

Sociometry, 32, 396-412.

Baum, A., \& Greenberg, C. I. (1975). Waiting for a crowd: The behavioral and perceptual effects of anticipating crowding. Journal of Personality and Social Psychology, 32, 671-679.

Burgoon, J. K. (1978). A communication model of personal space violations: Explication and an initial 
test. Human Communication Research, 4, 129-142.

Charles, K. E., \& Veitch, J. A. (2002). Environmental satisfaction in open-plan environments: 2. Effects of workstation size, partition height and windows. International report no. IRC-IR-845. Ottawa, ON: Institute for Research in Construction (IRC).

Dean, L. M., Willis, F. N., \& Hewitt, J. (1975). Initial interaction distance among individuals equal and unequal in military rank. Journal of Personality and Social Psychology, 32, 294-299.

Desor, J. (1972). Toward a psychological theory of crowding. Journal of Personality and Social Psychology, 21, 79-83.

Dosey, M. A., \& Meisels, M. (1969). Personal space and self-protection. Journal of Personality and Social Psychology, 11, 93-97.

Duke, M. P., \& Nowicki, S., Jr. (1972). A new measure and social learning model for interpersonal distance. Journal of Experimental Research in Personality, 6, 1-16.

Evans, G. W. (1979). Design implications of spatial research. In J. R. Aiello, \& A. Baum (Eds.), Residential crowding and design (pp. 197-216). New York: Plenum.

Evans, G. W., \& Lepore, S. J. (1992). Conceptual and analytic issues in crowding research. Journal of Environmental Psychology, 12, 163-173.

Fisher, J. D., \& Byrne, D. (1975). Too close for comfort: Sex differences in response to invasions of personal space. Journal of Personality and Social Psychology, 32, 15-21.

Fried, M., \& DeFazio, V. J. (1974). Territoriality and boundary conflicts in the subway. Psychiatry, 37, 4759.

Hall, E. T. (1966). The hidden dimension. New York: Doubleday.

Hall, J. A., Coats, E. J., \& LeBeau, L. S. (2005). Nonverbal behavior and the vertical dimension of social 
relations: A meta-analysis. Psychological Bulletin, 131, 898-924.

Horowitz, M., Duff, D., \& Stratton, L. (1964). Body-buffer zone. Archives of General Psychiatry, 146, 2435.

Hui, M. K., \& Bateson, J. E. G. (1991). Perceived control and the effects of crowding and consumer choice on the service experience. Journal of Consumer Research, 18, 174-184.

Jick, T. D., \& Mitz, L. F. (1985). Sex differences in work stress. Academy of Management Review, 10, 408420.

Kaya, N., \& Burgess, B. (2007). Territoriality: Seat preferences in different types of classroom arrangements. Environment and Behavior, 39, 859-876.

Kaya, N., \& Weber, M. J. (2003). Territorial behavior in residence halls: A cross- cultural study.

Environment and Behavior, 35, 400-414.

Keltner, D., Gruenfeld, D. H., \& Anderson, C. (2003). Power, approach and inhibition. Psychological Review, 110, 265-284.

Kelvin, P. (1973). A social psychological examination of privacy. British Journal of Social and Clinical Psychology, 12, 248-261.

Kimes, S. E., \& Robson, S. K. (2004). The impact of table characteristics on dining duration and spending. Cornell Hotel and Restaurant Administration Quarterly, 45, 333-346.

Kupritz, V. W. (2000). Privacy management at work: A conceptual model. Journal of Architectural and Planning Research, 17, 47-63.

Lott, D. F., \& Sommer, R. (1967). Seating arrangements and status. Journal of Personality and Social Psychology, 7, 90-95.

Mehrabian, A., \& Diamond, S. G. (1971). Seating arrangement and conversation. Sociometry, 34, 281- 
289.

Patterson, M. L., Mullens, S., \& Romano, J. (1971). Compensatory reactions to spatial intrusion.

Sociometry, 34, 114-121.

Proshansky, H. M., Ittelson, W. H., \& Rivlin, L. G. (1974). Freedom of choice and behavior in a physical setting. In H. M. Proshansky, W. H. Ittelson, \& L. G. Rivlin (Eds.), Environmental psychology (pp. 170-181). New York: Holt, Rinehart and Winston.

Robson, S. K. (2002). A review of psychological and cultural effects on seating behavior and their application to foodservice settings. Journal of Foodservice Research, 5, 89-107.

Schwartz, B. (1968). The social psychology of privacy. American Journal of Sociology, 48, 40-51.

Sommer, R. (1965). Further studies of small group ecology. Sociometry, 28, 337-348.

Sommer, R. (1969). Personal space: The behavioral basis of design. Englewood Cliffs, NJ: Prentice-Hall.

Sommer, R., \& Becker, F. D. (1969). Territorial defense and the good neighbor. Journal of Personality and

Social Psychology, 11, 85-92.

Vischer, J. C. (1996). Workplace strategies: Environment as a tool for work. New York: Chapman \& Hall.

Wakefield, K. L., \& Blodgett, J. G. (1996). The effect of the servicescape on customers' behavioral intentions in leisure service settings. Journal of Services Marketing, 10, 45-61.

Walden, T. A., Nelson, P. A., \& Smith, D. E. (1981). Crowding, privacy and coping. Environment and Behavior, 13, 205-224.

Webb, J. D., \& Weber, M. J. (2003). Influence of sensory abilities on the interpersonal distance of the elderly. Environment and Behavior, 35, 695-711.

Westin, A. (1967). Privacy and freedom. New York: Athenaeum.

Wheeler, L., Reis, H. T., \& Nezlek, J. (1983). Loneliness, social interaction, and sex roles. Journal of 
Personality and Social Psychology, 4, 943-953.

Whyte, W. H. (1980). The social life of small urban spaces. New York: Project for Public Spaces. 